\title{
The Influence of Stimulus Deviance on Electrophysiologic and Behavioral Responses to Novel Events
}

\section{Citation}

Daffner, Kirk R., Leonard F.M. Scinto, Vivian Calvo, Robert Faust, M. Marsel Mesulam, W. Caroline West, and Phillip J. Holcomb. 2000. "The Influence of Stimulus Deviance on Electrophysiologic and Behavioral Responses to Novel Events." Journal of Cognitive Neuroscience 12, no. 3: 393-406.

\section{Published Version}

10.1162/089892900562219

\section{Permanent link}

http://nrs.harvard.edu/urn-3:HUL.InstRepos:12605376

\section{Terms of Use}

This article was downloaded from Harvard University's DASH repository, and is made available under the terms and conditions applicable to Other Posted Material, as set forth at http:// nrs.harvard.edu/urn-3:HUL.InstRepos:dash.current.terms-of-use\#LAA

\section{Share Your Story}

The Harvard community has made this article openly available.

Please share how this access benefits you. Submit a story.

Accessibility 


\title{
The Influence of Stimulus Deviance on Electrophysiologic and Behavioral Responses to Novel Events
}

\author{
Kirk R. Daffner, Leonard F.M. Scinto, Vivian Calvo, and Robert Faust \\ Harvard Medical School
}

M. Marsel Mesulam

Northwestern University Medical School

W. Caroline West

Massachusetts General Hospital

\section{Phillip J. Holcomb}

Tufts University

\begin{abstract}
This study investigated the role of stimulus deviance in determining electrophysiologic and behavioral responses to "novelty." Stimulus deviance was defined in terms of differences either from the immediately preceding context or from long-term experience. Subjects participated in a visual event-related potential (ERP) experiment, in which they controlled the duration of stimulus viewing with a button press, which served as a measure of exploratory behavior. Each of the three experimental conditions included a frequent repetitive background stimulus and infrequent stimuli that deviated from the background stimulus. In one condition, both background and deviant stimuli were simple, easily recognizable geometric figures. In another condition, both background and deviant stimuli were unusual/unfamiliar figures, and in a third condition, the background stimulus was a highly unusual figure, and the deviant stimuli were simple, geometric shapes.
\end{abstract}

Deviant stimuli elicited larger N2-P3 amplitudes and longer viewing durations than the repetitive background stimulus, even when the deviant stimuli were simple, familiar shapes and the background stimulus was a highly unusual figure. Compared to simple, familiar deviant stimuli, unusual deviant stimuli elicited larger N2-P3 amplitudes and longer viewing times. Within subjects, the deviant stimuli that evoked the largest $\mathrm{N} 2-\mathrm{P} 3$ responses also elicited the longest viewing durations. We conclude that deviance from both immediate context and long-term prior experience contribute to the response to novelty, with the combination generating the largest $\mathrm{N} 2-\mathrm{P} 3$ amplitude and the most sustained attention. The amplitude of the N2-P3 may reflect how much "uncertainty" is evoked by a novel visual stimulus and signal the need for further exploration and cognitive processing.

\section{INTRODUCTION}

Orienting to and exploring novel events are central features of mammalian behavior that permit adaptive responses to a rapidly changing environment (Hunt, 1965; Sokolov, 1963; Fiske \& Maddi, 1961; Berlyne, 1960). Numerous studies have shown that subjects devote increased attentional resources to novel stimuli (Daffner, Scinto, Weintraub, Guinessey, \& Mesulam, 1992; Daffner, Scinto, Weintraub, Guinnessey, \& Mesulam, 1994; Daffner et al., 1998; Rohrbaugh, 1984; Loftus \& Mackworth, 1978; Noton \& Stark, 1971; Mackworth \& Morandi, 1967; Hunt, 1965; Berlyne, 1960). The orienting response to novel stimuli in-

cludes processes by which attention is shifted and further cognitive activity is directed towards potentially significant events (Daffner et al., 1998; Posner, 1986; Rohrbaugh, 1984; Öhman, 1979; Kahneman, 1973). The novelty N2-P3 wave of the event-related potential (ERP) has been shown to be a marker of the CNS component of the orienting response (Baudena, Halgren, Heit, \& Clarke, 1995; Halgren et al., 1995a; Hillyard \& Picton, 1987; Knight, 1984; Knight, 1986; Rohrbaugh, 1984; Naatanen \& Gaillard, 1983; Courchesne, 1978; Snyder and Hillyard, 1976; Squires, Squires, \& Hillyard, 1975; Roth, 1973; Ritter, Vaughan, \& Costa, 1968). ${ }^{1}$ It is evoked in all three of the 
primary sensory modalities in response to infrequent, "novel" stimuli that deviate from background. The novelty $\mathrm{N} 2-\mathrm{P} 3$ can be distinguished from the target $\mathrm{N} 2-\mathrm{P} 3$, a waveform in the same "family" of ERPs that tends to have a more posterior scalp distribution, longer latency and a sensitivity to stimuli that a subject must detect and either respond to or count (Picton, 1992; Hillyard \& Picton, 1987; Squires et al., 1975).

In a recent study, we found that novel visual stimuli elicit large novelty $\mathrm{N} 2-\mathrm{P} 3$ waves and increased subsequent attention as measured by the amount of viewing time subjects allocate to such stimuli (Daffner et al., 1998). Furthermore, the amplitude of the N2-P3 response strongly predicted the duration of subsequent viewing. Viewing duration was used as a measure of attention allocated to the visual stimuli (Daffner et al., 1992; Daffner et al., 1994; Daffner et al., 1998; Loftus \& Mackworth, 1978; Humphrey, 1972; Noton \& Stark, 1971; Vurpillot, 1968; Mackworth \& Morandi, 1967; Berlyne, 1960). As with many other studies, the background stimuli used were simple, familiar line drawings that appeared repetitively, and the novel stimuli were unfamiliar or unusual visual patterns presented in an infrequent, unpredictable fashion.

Which aspects of novelty contribute to the generation of the orienting response and subsequent exploratory behaviors? The current study focused on the role of stimulus deviance. Stimuli can deviate from immediate or long-term contexts. Detecting deviation from immediate context is dependent on working memory, a storage and processing system in which information about one's most recent experience is held and manipulated (Baddeley, 1992; GoldmanRakic, 1987). One role of working memory is to facilitate the comparison of incoming events with the immediately preceding sequence of stimuli. This comparison process is necessary for the organism to detect change or deviation. In addition to immediate contextual deviation, stimuli can also deviate from long-term experience, as when a stimulus is seen for the first time. ${ }^{2}$

A sizable literature now supports the hypothesis that the frontal lobes play an important role in working memory (Ungerlieder, Courtney, \& Haxby, 1998; McCarthy, 1995; Fuster, 1989; Goldman-Rakic, 1987). Consistent with this view are the data from monkeys showing the importance of frontal cortex in maintaining information about objects over short temporal intervals (Fuster, 1989; Goldman-Rakic, 1987). Interestingly, studies of stroke patients with focal lesions and seizure patients with depth electrodes suggest that the surface N2-P3 evoked by novel stimuli results from the activity of a distributed neural network with critical components in frontal cortex (Daffner et al., 2000a, in press; Baudena et al., 1995; Halgren et al., 1995a, Halgren et al., 1995b; Yamaguchi \& Knight, 1991b; Alain, Richer, Achim, \& Saint Hilaire, 1989; Wood \& McCarthy, 1985; Knight, 1984, 1986, 1996, 1997; Knight \& Scabini, 1998). In the patients with depth electrodes, the earliest response to deviant stimuli occurs in anterior regions (Baudena et al., 1995; Halgren et al., 1995a; Alain et al., 1989; Wood \& McCarthy, 1985). This observation led Halgren et al. (Baudena et al., 1995; Halgren et al., 1995a) to argue that the $\mathrm{N} 2-\mathrm{P} 3 \mathrm{a}$ may reflect the activity of frontal networks comparing incoming stimuli with the current context held in working memory, and signaling deviation from it.

However, if deviation from immediate context were the only factor influencing the novelty $\mathrm{N} 2-\mathrm{P} 3$, we would not expect the particular features of the deviating event to have an additional impact. To evaluate critical aspects of a stimulus such as familiarity or complexity, or to assess magnitude of deviance, requires access to information other than the immediately preceding context being held in working memory. If the amplitude of response or the surface distribution of the novelty $\mathrm{N} 2-\mathrm{P} 3$ were affected by such factors, it would suggest that other processes influence the $\mathrm{N} 2-\mathrm{P} 3$ beyond the registration of immediate contextual deviance. Work by Courchesne et al. (Courchesne, Hillyard, \& Galambos, 1975; Courchesne, 1978; Courchesne, Courchesne, \& Hillyard, 1978) supports the latter point of view. They found that highly deviant, unrecognizable visual stimuli evoked novelty P3 responses that were larger and more frontally distributed than simple, familiar visual stimuli that deviated from repetitive background events. However, their studies did not directly pit simple deviant stimuli against an unusual background stimulus, or unusual deviant stimuli against an unusual background stimulus. Also, their data collection ended approximately $800 \mathrm{msec}$ after stimulus onset, thus providing no information about their subjects' behavior beyond the limited temporal window of the ERP.

The current study examined how the different aspects of stimulus deviance influence the N2-P3 response and the allocation of attention as measured by viewing durations. Subjects participated in three tasks whose presentation order was counterbalanced. All of the tasks contained infrequent, deviant visual stimuli that differed from frequently presented repetitive background stimuli. In each task, the deviant stimuli occurred with the same degree of low probability $(p=.15)$ and unpredictability of appearance. The major difference among tasks was the relationship between the background and deviant stimuli, which, depending on the task, were selected either from a set of simple, easily recognizable geometric figures, or a set of unusual/unfamiliar line drawings. Figure 1 provides examples of the stimuli used. In one task (the All Simple Task), background and deviant stimuli 


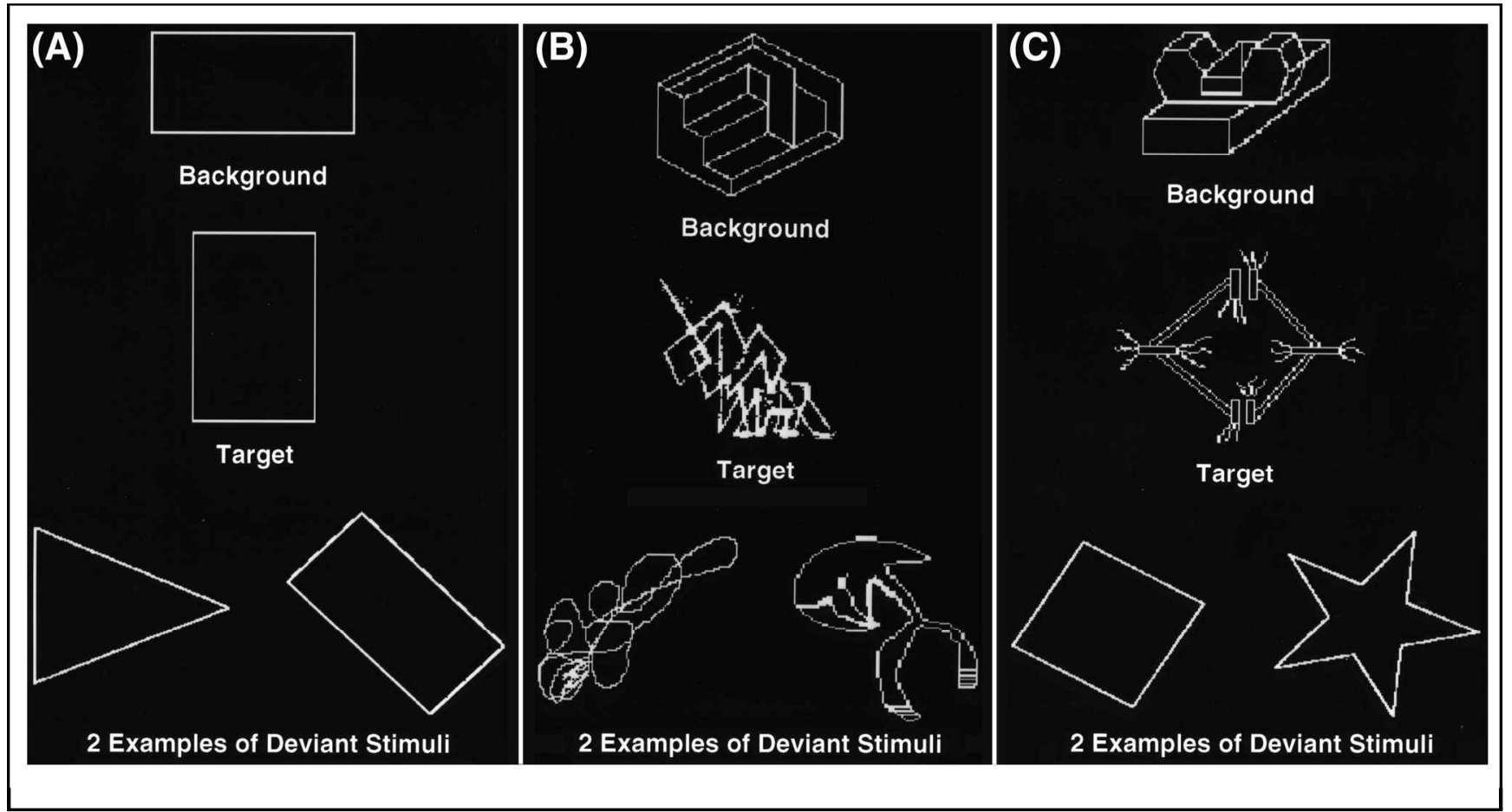

Figure 1. Examples of the repetitive background stimulus (70\% frequency), target stimulus (15\% frequency), and deviant stimuli (15\% frequency) from the (A) All Simple Task, (B) All Unusual Task, (C) Mixed Stimuli Task.

were simple geometric shapes. Thus, deviant stimuli were familiar, having been encountered many times outside of the experimental context. In the Mixed Stimuli Task, a repetitive background stimulus came from the set of unusual figures and the deviant stimuli were all simple, easily recognizable geometric shapes. This allowed us to examine the impact of deviance from immediate context, under a condition in which the repetitive background stimulus was more unusual than the deviant stimuli. In the All Unusual Task, the background and deviant stimuli used were from the set of unusual figures. Here, deviant stimuli differed from the immediately preceding context as well as from long-term prior experience.

Based on our previous work and on reports in the literature, we predicted that deviant stimuli would elicit larger N2-P3 amplitudes and longer viewing durations than repetitive background stimuli. We expected that this pattern would be observed even under the condition in which the deviant stimuli were more simple and familiar than the background stimulus, reflecting the important role of contextual deviance on the generation of the novelty $\mathrm{N} 2-\mathrm{P} 3$ and the orienting response. However, we suspected that any model of the novelty $\mathrm{N} 2-\mathrm{P} 3$ that relied solely upon the role of contextual deviance and working memory would fail to account for the impact of highly unusual deviant stimuli that had never been previously encountered. Consistent with Courchesne et al.'s work, we hypothesized that stimuli deviating from both immediate and long-term contexts would elicit larger, more anteriorly distributed $\mathrm{N} 2-\mathrm{P} 3$ waves and more attention, as measured by increased viewing durations, than stimuli that were only contextually deviant. Finally, we predicted that within individual subjects, the deviant stimuli that elicited the largest N2-P3 amplitude would be the ones looked at the longest.

\section{RESULTS}

\section{Description of the Wave Forms}

As can be seen in Figure $2 \mathrm{~A}-\mathrm{C}$, in each of the tasks, the deviant stimuli produced an early, anteriorly distributed negative-going component that peaked around $100 \mathrm{msec}$ (N1). At the most posterior sites, especially 01 and 02 , the ERPs were of the opposite polarity (P1) in the same latency range. Following N1, there was a positive-going P2, peaking around 170 msec, which was centrally distributed. Posteriorly (01/ 2 ), in the same temporal range, there was a deflection of opposite (negative) polarity, followed by a positive wave. In the 200-325 msec temporal window, the deviant stimuli evoked a large negativegoing wave (N2), which peaked around $260 \mathrm{msec}$ and was maximal at frontal sites. The N2 was followed by a P3 wave that had a parietal distribution. After the P3, there was a broad posteriorly distributed positive slow wave, which lasted until approximately 900 msec. The ERPs to target and background stimuli followed a similar pattern (i.e., N1, P2, N2, P3, and slow waves) with a few exceptions. Target P3s were 


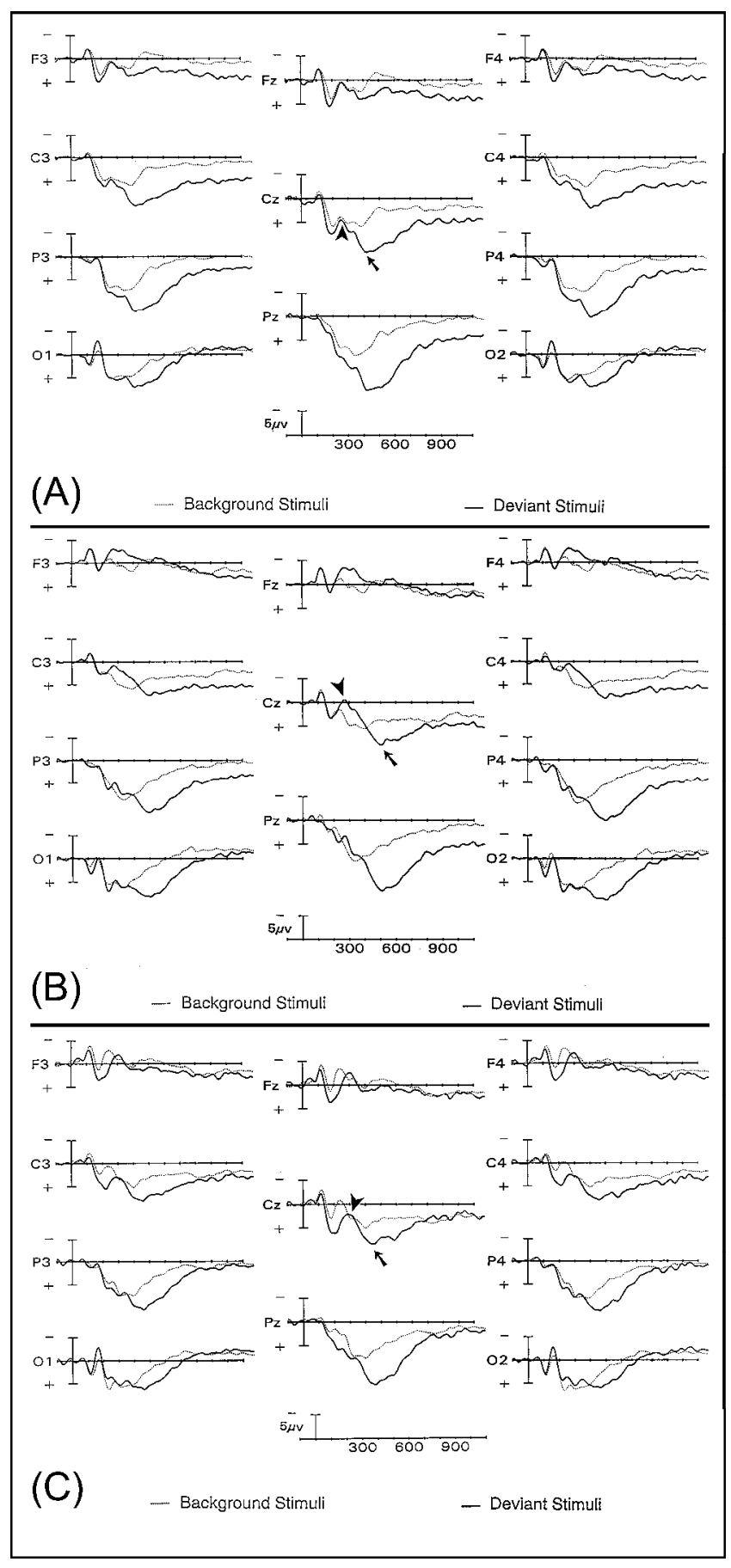

Figure 2. Grand average ERP plots in response to background stimuli (dotted lines) and deviant stimuli (solid lines) for (A) All Simple Task, (B) All Unusual Task, (C) Mixed Stimuli Task. Stimulus onset is indicated by the vertical calibration bar. For illustrative purposes, the arrowhead marks the $\mathrm{N} 2$ wave, and the arrow marks the $\mathrm{P} 3$ wave at the $\mathrm{Cz}$ electrode site in response to deviant stimuli.

maximal at parietal sites in all three tasks, while P3s to background stimuli had a more central-posterior distribution. The posteriorly distributed positive slow wave that followed the P3 was shorter for the background than target or deviant stimuli, lasting only until around $500 \mathrm{msec}$. Beginning between 600 and $700 \mathrm{msec}$, targets also elicited a broad negative wave at $\mathrm{Cz}$ and $\mathrm{Fz}$.

\section{N2-P3 Amplitude}

This study focused on the $\mathrm{N} 2-\mathrm{P} 3$ peak-to-peak wave in response to deviant and background stimuli (calculated by subtracting the peak amplitude of the N2 from the peak amplitude of the $\mathrm{P} 3$ ). The $\mathrm{N} 2-\mathrm{P} 3$ to deviant stimuli was larger than to background stimuli (main effect of stimulus type, midline sites: $F(1,23)=50.54, p<.00005$; lateral sites: $F(1,23)=41.77, p<.00005)$. This was true in each of the tasks, including the Mixed Stimuli Task in which the background stimulus was an unusual figure and the deviant stimuli were simple geometric shapes (midline: $F(1,23)=8.73, p<.008$; lateral sites: $F(1,23)$ $=10.73, p<.004)$. The $\mathrm{N} 2-\mathrm{P} 3$ had a central-parietal distribution for both background stimuli (main effect of electrode site, midline sites: $F(2,46)=8.81, p<.002$; lateral sites: $F(3,69)=5.96, p<.008)$ and deviant stimuli (main effect of electrode site, midline sites: $F(2,46)=28.57, p<.00005$; lateral sites: $F(3,69)=$ $10.83, p<.008){ }^{3}$ For deviant stimuli, there was no difference in scalp distribution of $\mathrm{N} 2-\mathrm{P} 3$ across tasks. However, for background stimuli, the N2-P3 evoked by the unusual background stimulus in the All Unusual Task and the Mixed Stimuli Task had a more anterior distribution than that evoked by the simple background stimulus in the All Simple Task (task by electrode site interaction, midline sites: $F(4,92)=4.42, p<.009$; lateral sites: $F(6,138)=7.40, p<.0003)$. In other words, the more unusual background stimuli produced more anterior $\mathrm{N} 2-\mathrm{P} 3$ s. Overall, the $\mathrm{N} 2-\mathrm{P} 3$ response to both background and deviant stimuli was larger at right hemisphere sites in the All Unusual and Mixed Stimuli Task, but not the All Simple Task (hemisphere by task interaction: $F(2,46)=6.06, p<.006)$. However, across all the three tasks, N2-P3 response was largest at rightcentral-parietal locations (hemisphere by electrode site interaction: $F(3,69)=5.71, p<.005)$.

$\mathrm{N} 2-\mathrm{P} 3$ response to the different stimulus types varied across tasks (task by stimulus type interaction, midline sites: $F(2,46)=6.68, p<.004$; lateral sites: $F(2,46)=3.70, p<.04)$. As shown in Figure 3 , the unusual deviant stimuli in the All Unusual Task elicited larger midline $\mathrm{N} 2-\mathrm{P} 3$ responses than the simple deviant stimuli in the All Simple Task $(F(1,23)=5.10$, $p<.04)$ or the Mixed Stimuli Task $(F(1,23)=6.39$, $p<.02)$. The magnitude of the difference between tasks was the same across electrode sites (no task by electrode site interaction). Although at lateral sites the N2-P3 response to deviant stimuli was also largest for the All Unusual Task, the difference did not reach statistical significance.

N2-P3 amplitude to the simple background stimulus in the All Simple Task was smaller in amplitude than to 


\section{N2-P3 Midline Sites}

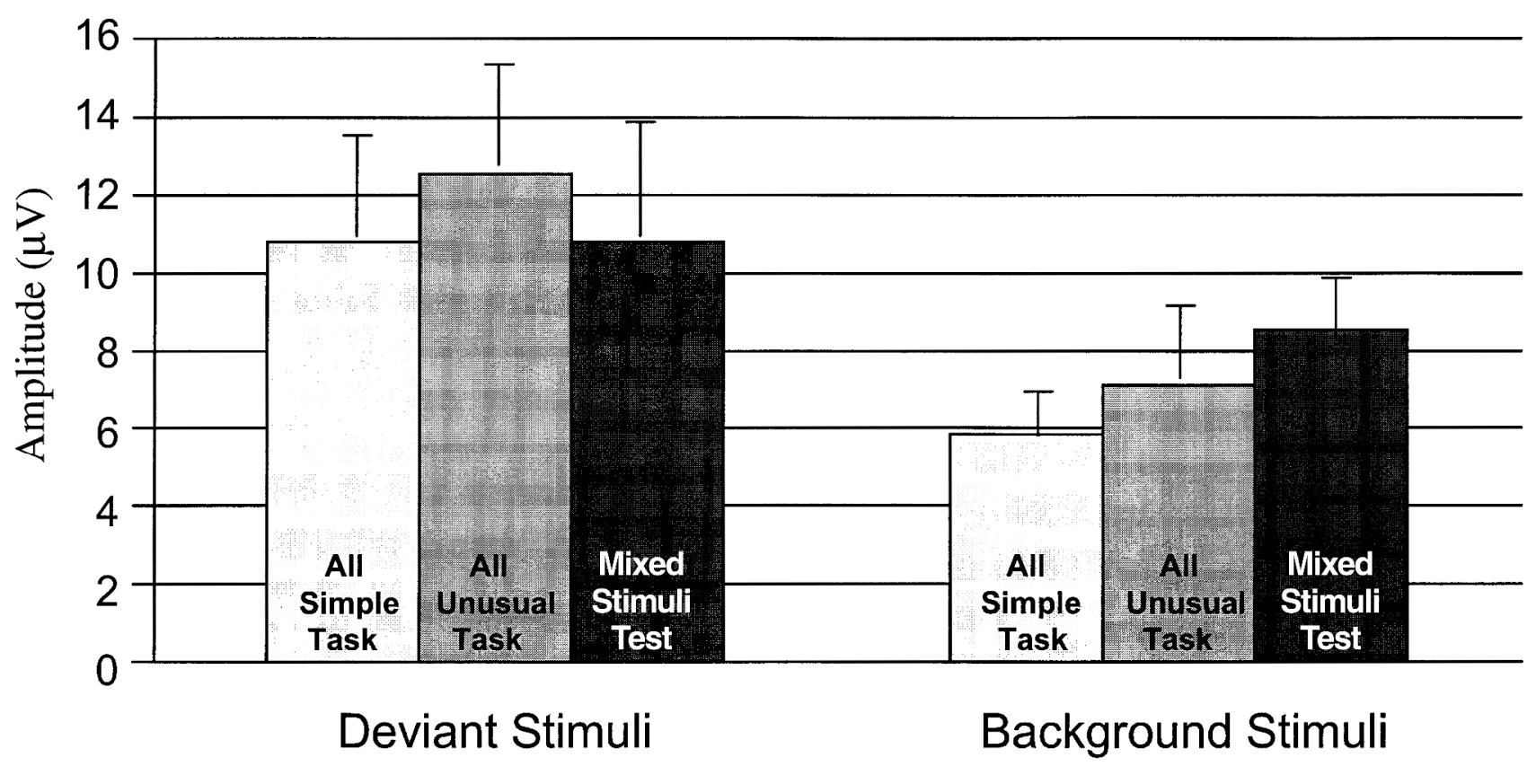

Figure 3. $\mathrm{N} 2-\mathrm{P} 3$ amplitude (in $\mu \mathrm{V}$ ) at midline sites (pooled across $\mathrm{Fz}, \mathrm{Cz}$, and $\mathrm{Pz}$ ) in response to deviant and background stimuli (Mean \pm SEM) for each of the tasks.

the unusual background stimuli in the All Unusual Task (midline site: $\mathrm{F}(1,23)=5.15, \mathrm{p}<.04$; lateral site: $\mathrm{F}(1,23)=3.64, \mathrm{p}<.07)$ and the Mixed Stimuli Task (midline site: $\mathrm{F}(1,23)=32.24, \mathrm{p}<.00005$; lateral sites: $\mathrm{F}(1,23)=10.06, \mathrm{p}<.005)$. There was no difference between the latter two tasks at lateral sites, while at midline sites, N2-P3 amplitude was larger to the background stimulus in the All Unusual Task $(\mathrm{F}(1,23)=9.21$, $\mathrm{p}<.006)$.

\section{P3 Latency}

Across all tasks, P3 latency to deviant stimuli was shortest at frontal sites, while P3 latency to background stimuli was shortest at parietal sites (stimulus type by electrode sites interaction, midline sites: $F(2,46)=13.36, p<.00005$; lateral sites: $F(3,69)=12.64, p<.0002)$. P3 latency was shorter in response to background stimuli than deviant stimuli (main effect of stimulus type, midline sites: $F(1,23)$ $=66.54, p<.00005$; lateral sites: $F(1,23)=127.51, p<$ $.00005)$. P3 latency to the different stimulus types varied across tasks (task by stimulus type interaction, midline sites: $F(2,46)=4.59, p<.03$; lateral sites: $F(2,46)=8.39$, $p<.002)$. P3 latency to the unusual deviant stimuli in the All Unusual Task was longer than to the simple deviant stimuli in the All Simple Task (midline sites: $F(1,23)=$
36.56, $p<.00005$; lateral sites: $F(1,23)=35.72, p<$ $.00005)$ or the Mixed Stimuli Task (midline sites: $F(1,23)$ $=13.26, p<.0005$; lateral sites: $F(1,23)=10.91, p<$ $.004)$. P3 latency in response to the simple background stimulus in the All Simple Task was shorter than in response to the unusual background stimulus in the All Unusual Task (midline sites: $F(1,23)=15.19, p<.0008$; lateral sites: $F(1.23)=5.68, p<.03)$ or the Mixed Stimuli Task (midline sites: $F(1,23)=21.98, p<.0002$; lateral site: $F(1,23)=24.54, p<.0002)$. No hemispheric effects were noted in any of the tasks.

\section{Viewing Durations}

Viewing durations on the different stimulus types varied across tasks (task by stimulus type interaction: $F(4,92)=22.01, p<.00005)$. As illustrated in Figure 4 , viewing durations on the unusual deviant stimuli in the All Unusual Task were significantly longer than on the simple deviant stimuli in the All Simple Task $(F(1,23)=26.48, p<.00005)$ or the Mixed Stimuli Task $(F(1,23)=18.70, p<.004)$. There were no significant differences in viewing durations on the simple deviant stimuli of the latter two tasks. However, subjects looked at deviant stimuli longer than the repetitive background stimulus in each task (main 


\section{Viewing Durations}

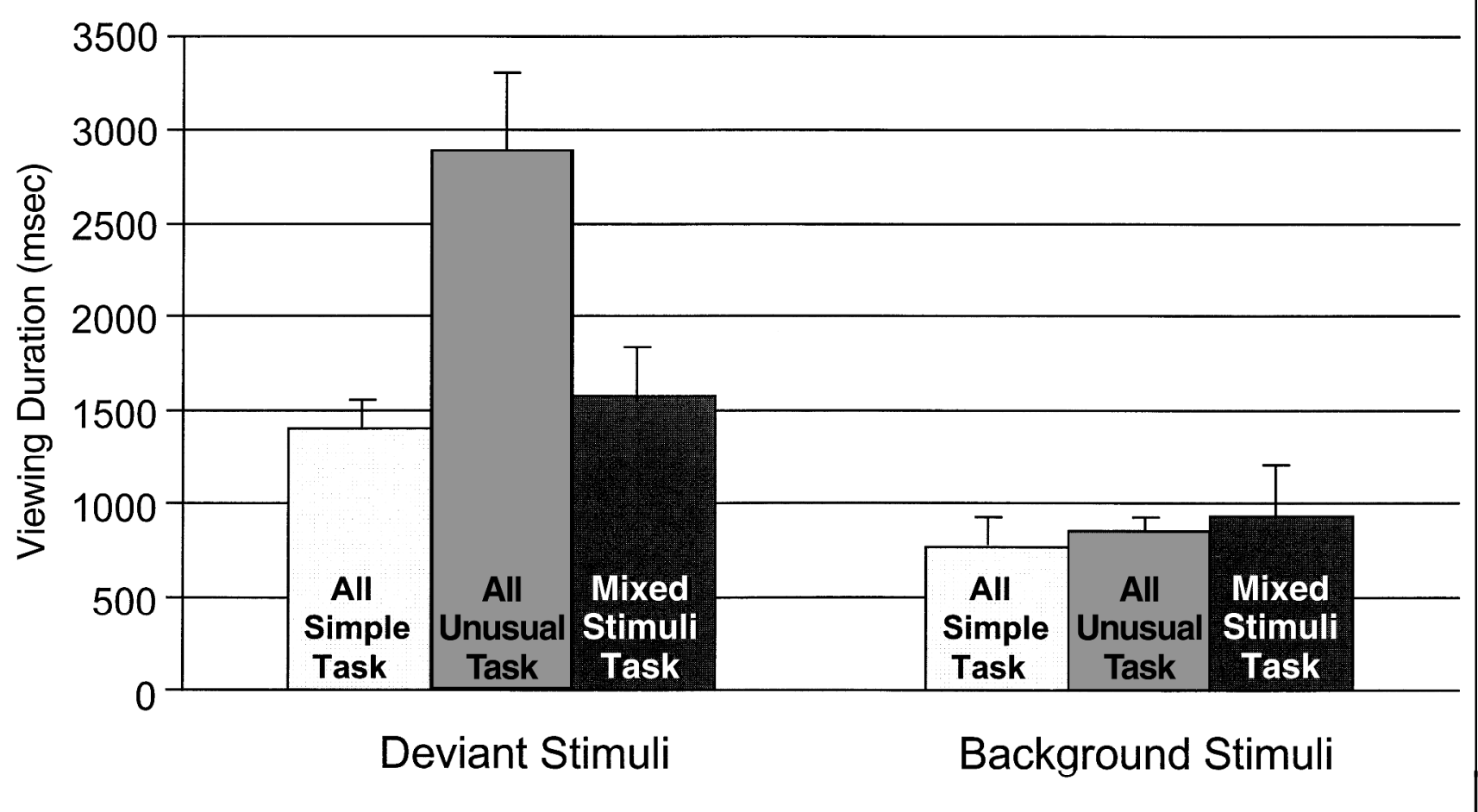

Figure 4. Viewing duration on deviant and background stimuli in msec (Mean $\pm S E M$ ) for each of the tasks.

effect of stimulus type $(F(1,23)=32.14, p<.00005)$, including the Mixed Stimuli Task $(F(1,23)=13.37, p$ $<.002)$. Viewing durations were shorter on the simple background stimuli in the All Simple Task than on the unusual background stimuli in the Mixed Stimuli Task $(F(1,23)=13.47, p<.002)$ or the All Unusual Task $(F(1,23)=3.96, p<.06)$.

\section{Immediate versus Long-term Deviance}

The results presented so far indicate that deviation from both immediate context and from long-term contexts contribute to the electrophysiologic (N2-P3) and behavioral responses to novelty. However, it is not clear whether the effects are additive or interactive. To ex- amine this issue, the results from the All Simple Task versus the All Unusual Task were explored further. This allowed for a direct look at whether being an unusual rather than a simple figure has a greater impact on the response to deviant stimuli than it does on the response to repetitive background stimuli.

As shown in Table 1, deviant stimuli evoked larger midline N2-P3 amplitudes than background stimuli (main effect of stimulus type, $F(1,23)=66.09, p<$ .00005). Similarly, unusual stimuli evoked larger N2-P3 responses than simple stimuli (main effect of task, $F(1,23)=10.67, p<.0004)$. However, there was no stimulus type by task interaction $(F(1,23)=.21)$, suggesting that the effects on $\mathrm{N} 2-\mathrm{P} 3$ amplitude of the two variables were additive.

Table 1. Mean ( \pm standard deviations) of $N 2-\mathrm{P} 3$ Amplitude (in $\mu \mathrm{V}$ ) and Viewing Duration (in msec) for Background and Deviant Stimuli in the All Simple Task and in the All Unusual Task

\begin{tabular}{lccccc}
\hline & \multicolumn{2}{c}{ N2-P3 Amplitude $(\mu V)$} & & \multicolumn{2}{c}{ Viewing Duration (msec) } \\
\cline { 2 - 3 } & All Simple Task & All Unusual Task & & All Simple Task & All Unusual Task \\
\hline Background stimuli & $5.85(3.68)$ & $7.12(3.67)$ & $763(377)$ & $855(441)$ \\
Deviant stimuli & $10.80(4.88)$ & $12.52(5.30)$ & $1,398(831)$ & $2,892(1866)$ \\
\hline
\end{tabular}


Figure 5. Grand average ERP plots for deviant stimuli whose viewing durations were $>50$ th percentile (thick line) versus deviant stimuli whose viewing durations were $<50$ th percentile (thin line). In order to derive the grand average, a median split was performed on the viewing duration data of deviant stimuli for each individual subject collapsed across the three tasks, and the ERPs to deviant stimuli above and below the median determined. For illustrative purposes, the arrowhead marks the N2 wave, and the arrow marks the $\mathrm{P} 3$ wave at the $\mathrm{Cz}$ electrode site.
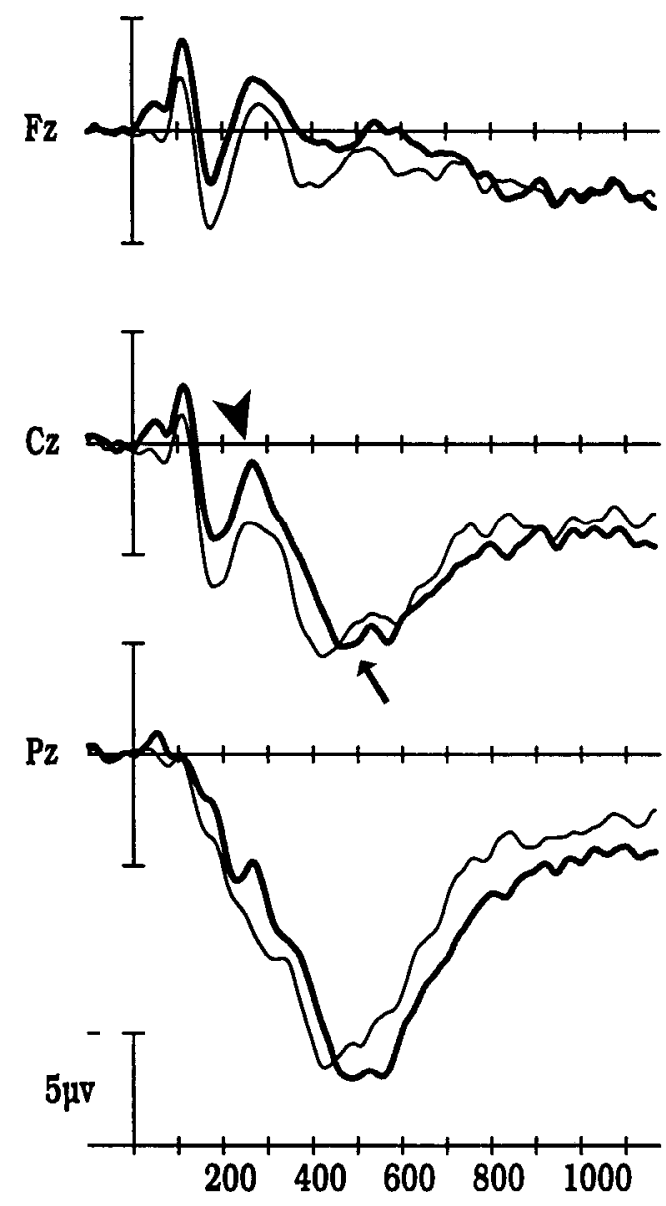

Deviants less than 50 th percentile
Deviants greater than 50 th percentile
As with the N2-P3 amplitude, deviant stimuli elicited longer viewing durations than background stimuli (main effect of stimulus type, $F(1,23)=34.57$, $p<.00005)$, and unusual stimuli elicited longer viewing durations than simple stimuli (main effect of task, $F(1,23)=26.45, p<.00005)$. However, in contrast to the $\mathrm{N} 2-\mathrm{P} 3$ results, there was a significant stimulus type by task interaction $(F(1,23)=25.30, p<.00005)$. For viewing durations, being an unusual stimulus had a greater impact on deviant stimuli than it did on repetitive background stimuli.

\section{Relationship Between N2-P3 and Viewing Durations Within Subjects}

For each individual subject, a median split was performed on the viewing duration data of the deviant stimuli collapsed across the three tasks. Figure 5 illustrates the grand average ERPs at midline sites for the deviant stimuli whose viewing durations were greater than the fiftieth percentile compared to those for the deviant stimuli whose durations were below the fiftieth percentile. Analysis of the N2-P3 amplitude revealed that it was significantly larger for the deviant stimuli that were viewed the longest $(F(1,23)=6.30$, $p<.02)$. There was no difference in magnitude across electrode sites. ${ }^{4}$

\section{DISCUSSION}

Novelty is a relative concept, dependent, in part, on a particular individual's prior experience and the context in which an event occurs. Something can be novel with respect to a person's recent experience (e.g., within the context of an experiment) or total experience (determined by events prior to an experiment). Novel stimuli may represent patterns that have never been encountered before or may contain some familiar elements in new combinations or arrangements. Furthermore, novel stimuli can vary in the degree to which they resemble other stimuli and the time elapsed since the occurrence of similar patterns. 
This study investigated the extent to which electrophysiologic and behavioral responses to novel stimuli are influenced by deviance from immediate and longterm contexts. In each task, trials displaying the reappearance of a repetitive background stimulus minimized deviation from what was being held in active working memory. Each task included infrequent, randomly presented novel stimuli. The tasks differed in the degree to which novel stimuli were deviant and unfamiliar.

The results demonstrate that within each task, deviant stimuli elicited significantly larger N2-P3 waves than background stimuli. This occurred even when the deviant stimuli were simple and the background stimulus was unusual (Mixed Stimuli Task). This finding provides compelling evidence that deviation from immediate context, in and of itself, evokes an orienting response (as indexed by the N2-P3), regardless of the degree of familiarity or complexity of the novel event. However, comparisons across tasks revealed that the $\mathrm{N} 2-\mathrm{P} 3$ in response to unfamiliar deviants (All Unusual Task) was larger than in response to simple, easily recognized deviants (All Simple and Mixed Stimuli Tasks). This strongly suggests that deviation from long-term contexts also contributes to the magnitude of the $\mathrm{N} 2-\mathrm{P} 3 .^{5}$

These results are consistent with Courchesne et al.'s work (Courchesne et al., 1975; Courchesne, 1978; Courchesne et al., 1978). They demonstrated that deviant stimuli that were not easily encodable (i.e., unfamiliar), described as "unrecognizable," quasirandom colored objects, evoked larger novelty P3s than deviant stimuli that could easily be recognized by subjects. However, they showed that even simple, easily recognized visual stimuli that deviate from a sequence of repetitive background events evoke the novelty P3 response. Courchesne et al.'s work was extended in the current study by directly comparing a background stimulus that was a highly unusual figure with deviant stimuli that were simple, easily recognizable line drawings. Moreover, the temporal window of observation was expanded to examine subsequent exploratory behavioral responses to background and deviant stimuli.

Recently, Polich et al. demonstrated that the magnitude of deviation of nontarget stimuli from background stimuli influenced the size of the P3 response to the nontarget stimuli (Katayama \& Polich, 1998), especially in the auditory modality (Comerchero \& Polich, 1998). Greater deviation was associated with larger responses. Furthermore, in the context of a difficult target-background discrimination task, requiring increased attentional effort, nontargets that deviated greatly from backgrounds evoked an anteriorly distributed P3a wave. The authors interpret this response as reflecting frontal lobe activity that temporarily redirects attention to a salient nontarget. Since in the current study in which target discrimination diffi- culty was not systematically manipulated across tasks, it is unclear whether this factor played a role in the results. Also unclear is whether it is appropriate to interpret our study's differences in $\mathrm{N} 2-\mathrm{P} 3$ amplitude in terms of magnitude of deviation from the background stimulus rather than the nature of the deviation (i.e., from immediate versus long-term contexts). One could argue that the magnitude of deviation from the highly unusual background stimulus in the All Unusual Task (where deviant stimuli were other highly unusual figures) was smaller than from the highly unusual background stimulus in the Mixed Stimuli Task (where deviant stimuli were simple figures). However, the N2-P3 response to deviant stimuli was much larger in the All Unusual Task than the Mixed Stimuli Task, suggesting that deviation from long-term context and not just the magnitude of deviation influenced the size of the response.

Although traditionally researchers have emphasized the autonomic and reflexive features of the orienting ("what is it?") response, there is evidence that it is signaling that a novel event requires additional attentional processing because of its potential behavioral significance (Daffner et al., 1998; Posner, 1986; Rohrbaugh, 1984; Öhman, 1979; Kahneman, 1973). The novelty $\mathrm{N} 2-\mathrm{P} 3$ wave may be conceptualized as reflecting the activity of a gateway in this decision process. Our previous work supported this view by showing that the amplitude of the N2-P3 wave strongly predicted subsequent viewing durations. The current study provides additional evidence for this hypothesis, as the behavioral responses to deviant stimuli follow a pattern similar to that of the electrophysiologic data (N2-P3 amplitude). Deviant stimuli elicited more attention, as measured by longer viewing durations, than background stimuli, even when the deviant stimuli were simple and the background stimulus was unusual (Mixed Stimuli Task). Visual stimuli that were deviant in terms of both immediate and long-term contexts generated the longest viewing times (All Unusual Task). Moreover, within subjects, the N2-P3 amplitude in response to deviant stimuli "predicted" viewing durations. The particular deviant stimuli that evoked the largest N2-P3 waves were explored the longest. ${ }^{6}$

Further analyses revealed that deviation from immediate and long-term contexts are independent factors, whose impact on $\mathrm{N} 2-\mathrm{P} 3$ amplitude is additive. In looking at the All Simple Task versus the All Unusual Task, there were main effects of stimulus type (whether or not a stimulus deviated from immediate context) and task (whether or not a stimulus was unusual or simple). However, there was no interaction between these variables. Thus, the increase in $\mathrm{N} 2-\mathrm{P} 3$ response to unusual compared to simple deviant stimuli was of similar magnitude to the increase in $\mathrm{N} 2-\mathrm{P} 3$ response to unusual compared to simple background stimuli. Within the framework being devel- 
oped, the novelty $\mathrm{N} 2-\mathrm{P} 3$ may be interpreted as indexing activity that signals that a stimulus requires additional processing resources, either (1) because it represents a change from immediate context or (2) because it is not readily encodable (due to its unfamiliarity or complexity). In the current study, additional processing was measured in terms of viewing time devoted to a stimulus. In contrast to the N2-P3 response, for viewing durations, deviation of a stimulus from long-term experience appears to "potentiate" and not simply add to its deviation from immediate context. Further study is required to elucidate the processes that facilitate this interaction and to determine if it has an electrophysiologic correlate.

Lesion and depth electrode studies strongly indicate that the activity indexed by the surface novelty N2-P3 is subserved by a distributed network that includes dorsolateral prefrontal cortex, anterior cingulate, temporal-parietal junction, and hippocampus (Baudena et al., 1995; Halgren et al., 1995a, Halgren et al., 1995b; Yamaguchi \& Knight, 1991b; Alain et al., 1989; Wood \& McCarthy, 1985; Knight, 1984, 1986, 1996, 1997; Knight \& Scabini, 1998). In the patients with depth electrodes, the earliest response occurs in anterior regions (Baudena et al., 1995; Halgren et al., 1995a; Alain et al., 1989; Wood \& McCarthy, 1985). Consistent with this observation, the current study found that P3 latency in response to either simple or unusual deviant stimuli was shortest at frontal sites. As suggested by Halgren et al. (Baudena et al., 1995; Halgren et al., 1995a), the frontal components of this network may play a critical role in signaling when incoming stimuli deviate from information held in working memory.

Interestingly, the results from the current study raise the possibility that brain regions involved in the $\mathrm{N} 2-\mathrm{P} 3$ response to stimuli that deviate from long-term contexts may be similar to those that are involved in response to stimuli that deviate from immediate context. No differences were found in the scalp distribution of the N2-P3 response to the unusual versus simple deviants (i.e., no task by electrode site interaction at midline or lateral sites). The neural system concerned appears capable of making a relatively rapid determination of an event's deviance from immediate as well as long-term contexts. The assessment that a visual image is unfamiliar presumably occurs through a monitoring system that follows the output of a highly parallel search process. The frontal networks probably play an important role in assessing deviance from long-term experience by helping to determine the plausibility that a stimulus was previously encountered and by monitoring the degree of familiarity evoked by an event (Tulving, Markowitsch, Craik, Habib, \& Houle, 1996; Metcalfe, 1993).

Although the novelty N2-P3 in the current experiments was more anteriorly distributed than the target $\mathrm{N} 2-\mathrm{P} 3$, it appears to have less of a frontal distribution than in an earlier study (Daffner et al., 1998) in which deviants were unusual and backgrounds were simple. The source of this difference remains to be determined. It may be due to the fact that there was less contrast between deviant and background stimuli in the current tasks. Alternatively, three times the number of trials were employed, which may have reduced the impact of novelty and led to a greater habituation of the frontal electrophysiologic response to novel stimuli, as has been observed by Courchesne (Courchesne et al., 1975; Courchesne, 1978) and Knight (Knight, 1984; Yamaguchi \& Knight, 1991a).

The novelty N2-P3 elicited by deviant stimuli probably consists of overlapping (anterior) $\mathrm{N} 2-\mathrm{P} 3 \mathrm{a}$ and (posterior) N2-P3b components. The N2-P3a component is measured by activity at fronto-central sites. It is not believed to be dependent on voluntary attention and can be evoked by deviant stimuli under conditions in which subjects are actively ignoring the stimulus set (Knight \& Scabini, 1998; Snyder \& Hillyard, 1976; Squires et al., 1975). The N2-P3a occurs earlier than the $\mathrm{N} 2-\mathrm{P} 3 \mathrm{~b}$, and may represent a switch or realignment of attention toward the (unexpected) deviant stimulus, allowing for controlled attentional processing (Escera, Alho, Winkler, \& Naatanen, 1998; Naatanen, 1992). The N2-P3b component is measured by activity at posterior sites and is believed to be dependent upon voluntary attention (Knight \& Scabini, 1998; Picton, 1992; Johnson, 1986; Snyder \& Hillyard, 1976; Squires et al., 1975). Deviant stimuli have been shown to evoke a larger novelty N2-P3 response when they are passively attended rather than ignored (Holdstock \& Rugg, 1995). The greatest difference in magnitude between these conditions occurs at parietal (P3b) sites, which may be indexing the allocation of additional attentional resources. Given this observation, it is not surprising that we found a robust (posterior) novelty $\mathrm{P} 3 \mathrm{~b}$ component in the current tasks, as subjects were actively attending to the stimulus set in order to decide how long to look at each of its members. In keeping with this notion, we have previously noted (Daffner, Mesulam, West, \& Holcomb, 1996) that under a condition in which subjects controlled viewing durations, deviant stimuli evoked a larger posterior novelty $\mathrm{N} 2-\mathrm{P} 3 \mathrm{~b}$ wave than analogous deviant stimuli under a typical condition in which subjects viewed stimuli more passively. In short, the $\mathrm{N} 2-\mathrm{P} 3 \mathrm{a}$ and $\mathrm{N} 2-\mathrm{P} 3 \mathrm{~b}$ components of the novelty $\mathrm{N} 2-$ P3 wave most likely represent different aspects of the processing of deviant stimuli. Both components are enhanced in response to stimuli that deviate from immediate and long-term contexts.

Placing the current findings within a broader context, the "family" of N2-P3 ERPs may be viewed as registering the activity of complementary neural systems that allow individuals to anticipate the occurrence of significant environmental events (target 
$\mathrm{N} 2-\mathrm{P} 3$ ), while being ready to respond to unexpected and potentially important discrepancies from the status quo (novelty N2-P3) (Hillyard \& Picton, 1987). While the amplitude of the target $\mathrm{N} 2-\mathrm{P} 3$ has been shown to partially depend on the extent to which an individual was actively attending to a stimulus designated as a target (Picton, 1992; Donchin \& Coles, 1988; Johnson, 1986; Desmedt, 1981; Duncan-Johnson \& Donchin, 1977), our data suggest that the amplitude of the novelty N2-P3 indexes the shift of attention toward a stimulus that is potentially significant. Moreover, while the amplitude of the target $\mathrm{N} 2-\mathrm{P} 3$ is believed to reflect the degree to which prior uncertainty is resolved about the nature of a stimulus (Hillyard \& Picton, 1987; Johnson, 1986; Ruchkin \& Sutton, 1978; Sutton, Braren, Zubin, \& John, 1965), our data suggest that the amplitude of the novelty $\mathrm{N} 2-\mathrm{P} 3$ reflects the degree to which uncertainty is evoked by a stimulus.

It is likely that the frontal networks contribute to the generation of the novelty $\mathrm{N} 2-\mathrm{P} 3$ and subsequent exploratory behavior in several ways that include maintaining current context on line (working memory), assessing deviation from it, signaling unfamiliarity, and calling for additional attentional processing. The results of our study support the thesis that N2-P3 amplitude reflects the degree to which an organism's model of the environment may need to be updated (Donchin, 1981; Donchin \& Coles, 1988). However, in contrast to the view that the target N2P3 represents "closure" of cognitive processing (Desmedt, 1981), the novelty N2-P3 seems to be indicating a call to extend it, through the allocation of further attentional resources. Not only the amplitude of the $\mathrm{N} 2-\mathrm{P} 3$, but also subsequent exploratory activity were commensurate with the degree of uncertainty generated by the novel event. Deviance from immediate context as well as from long-term prior experience contributed to the response to novelty, with the combination of these factors producing the largest $\mathrm{N} 2-\mathrm{P} 3$ amplitude and most sustained attention.

\section{METHODS}

\section{Subjects}

Twenty-four right-handed native English-speaking undergraduates ( 15 females; mean age 20.54 years [ \pm 1.32]) participated in the present study. None had known neurological problems or learning disabilities. Written informed consent was obtained from all subjects prior to beginning the study. Subjects were paid for their time.

\section{Experimental Tasks}

There were three experimental tasks, whose order was counterbalanced across subjects. Each task included three categories of visual stimuli: (1) a repetitive Background Stimulus (70\% frequency); (2) an infrequent Target Stimulus (15\% frequency); and (3) infrequent Deviant Stimuli (15\% frequency), consisting of a set of unique figures. All stimuli either came from a set of simple geometric figures or a set of unusual/unfamiliar figures (e.g., fragmented or "impossible" objects), many of which were from the collection of drawings that have been used by Kosslyn et al. (1994) and Kroll and Potter (1984). The particular stimuli assigned to each task were randomly chosen from the two sets of figures noted above.

In one task, background, target, and deviant stimuli all came from the set of simple, easily recognizable, geometric figures (All Simple Task). In another task, background, target, and deviant stimuli all came from the set of unusual/unfamiliar stimuli (All Unusual Task), and in a third task, the background stimulus and the target stimulus were from the set of unusual figures, while the deviant stimuli came from the set of simple, recognizable, geometric figures (Mixed Stimuli Task). (See Figure $1 \mathrm{~A}-\mathrm{C}$.) The deviant stimuli in each of the tasks were only shown one time each.

Each task presented 250 line drawings, white on black background displayed on a 16-in. color monitor. Each figure subtended a visual angle of approximately $2.5^{\circ}$ along its longest dimension. These stimuli appeared within a fixation box subtending a visual angle of approximately $3.5 \times 3.5^{\circ}$, that remained on the screen at all times. Stimuli were presented in pseudorandom order with the additional constraints that no more than two deviant stimuli were presented consecutively, and that each block of 50 stimuli had the same number of background stimuli and approximately the same number of target and deviant stimuli.

\section{Procedure}

Subjects were introduced to the laboratory setting and, following electrode placement (see below), were seated in front of a computer monitor in a sound attenuated room. Subjects were told that the experiment involved the study of brain wave responses as they looked at different kinds of pictures. They were informed that they would be viewing a set of pictures and that they could look at each picture for however long or short they liked. They controlled the viewing duration by a button press that triggered the onset of the next stimulus. They were explicitly informed that they would not be asked questions about the pictures at the conclusion of the experiment. Subjects also were asked to respond to the designated target stimulus by pressing a foot pedal (ipsilateral to the button press). The targets were called "Sequence Markers" and subjects were told that they were included in the task to help the experimenters keep track of where they were in the sequence of drawings. As with the other stimuli, subjects controlled 
how long they looked at each of the targets. The 250 stimuli for each task were presented in five blocks of 50 stimuli each, with a brief break between each block. Longer breaks were taken between each task. The laterality of the responding hand and foot was counterbalanced across subjects. Although viewing durations were calculated by subtracting the stimulus onset time from the button press time, all stimuli were displayed for a minimum duration of $600 \mathrm{msec}$. The interval between the offset of one stimulus and the onset of the next stimulus ranged between 800 and 1300 msec.

\section{ERP Recordings}

An electrode cap (Electro-Cap International) was used to hold the 13 active electrodes to the scalp, including three midline sites (Fz, Cz, Pz) and 10 lateral sites (O1, O2, P3, P4, C3, C4, F3, F4, F7, F8) based on international 10-20 system locations. These sites were all referenced to the left mastoid and the impedance between each recording site, and the reference was reduced to less than 5,000 $\Omega$. Two electrodes (left mastoid reference) were placed to monitor for eye artifacts-one beneath the left eye (to check for eye blinks and vertical eye movements) and the other to the right of the subject's right eye (to check for lateral eye movements). A final electrode was placed over the right mastoid (referenced to the left) to monitor for asymmetrical mastoid activity. (None was found.) The EEG was amplified by a Grass Model 12 Neurodata Acquisition system ( -3 dB cutoffs of 0.01 and $100 \mathrm{~Hz}$ ) and continuously digitized $(200 \mathrm{~Hz})$ by an IBM compatible computer yielding 1,280 msec of data from each electrode site, beginning $100 \mathrm{msec}$ before stimulus onset.

\section{Data Analysis}

Analyses reported here involve comparisons between responses to background and deviant stimuli that allowed us to address the main questions of the study. The task demand for targets differed from either background or deviant stimuli by requiring the identification of specific figures and the preparation of an additional motor response (foot pedal).

A continuous record of the raw EEG was stored on a hard disk. Off-line, EEG epochs for the two stimulus types (background, deviant) were averaged separately to form the ERPs for each respective condition. Trials with eye blinks ( $>50 \mu \mathrm{V}$ peak-to-peak amplitude in the channel below the left eye), eye movements ( $>50 \mu \mathrm{V}$ peak-to-peak amplitude in the channel next to the right eye), or amplifier blocking were excluded from data analysis. The temporal intervals used for defining N2 and P3 in each task were determined after reviewing the individual ERP plots for all subjects. The P3 latency was found to be earlier for the All Simple Task than the other two tasks. For the All Simple Task, N2 was defined as the peak negative amplitude occurring 200-300 msec after stimulus onset, and P3 was the peak positive amplitude occurring 300-525 msec after stimulus onset. For the All Unusual Task and the Mixed Stimuli Task, N2 was defined as the peak negative amplitude occurring 200-325 msec after stimulus onset, and $\mathrm{P} 3$ was the peak positive amplitude occurring 325-525 msec after stimulus onset. Peak amplitudes were measured with respect to the average of the 100 msec prestimulus baseline. N2-P3 peak-topeak amplitude was calculated by subtracting the value for N2 from the value for $\mathrm{P} 3$.

Data were analyzed using repeated measures ANOVAs (BMDP2V). Midline and lateral sites were analyzed separately. There were two levels of stimulus type (background, novel) and three levels of task (All Simple, All Unusual, Mixed Stimuli Tasks). For ERP measures, there were three midline electrode sites (Fz, Cz, Pz) and four lateral electrode sites (01/2, P3/ 4, C3/4, F3/4), with two levels each (one for each hemisphere). Between task analyses that yielded a significant main effect or interaction involving the task variable resulted in planned comparisons, contrasting the three levels (All Simple Task versus All Unusual Task versus Mixed Stimuli Task). Follow-up analyses on task by stimulus type interactions contrasted the three tasks for each stimulus type separately. Also, a further set of analyses was run to look for potential interactions between stimulus type (background vs. deviant) and stimulus familiarity (simple vs. unusual). In looking at scalp site interactions with other variables, the data were normalized using a $z$ score technique (Kounios \& Holcomb, 1994) similar to the method recommended by McCarthy and Wood (1985) to avoid problems associated with interpreting site by factor interactions using ANOVA. Only electrode site interactions that remained significant after normalizing the data are reported. The Geisser-Greenhouse correction (Geisser \& Greenhouse, 1959) was applied for all repeated measures with greater than 1 degree of freedom.

\section{Acknowledgments}

We thank Dr. S. M. Kosslyn and Drs. J. F. Kroll and M. C. Potter for the use of their stimulus sets. We acknowledge Barbara Vericker, Lisa Preston, and Lise Bliss for their expert secretarial and administrative assistance.

Reprint requests should be sent to Kirk R. Daffner, Division of Cognitive and Behavioral Neurology, Brigham and Women's Hospital, Harvard Medical School, 221 Longwood Avenue, Boston, MA 02115.

\section{Notes}

1. There is no consensus on the naming of the novelty ERPs, that have variably been called the novelty P300 (e.g., Yamaguchi \& Knight, 1991a; Knight, 1984, Knight, 1986), 
novels P3 (e.g., Courchesne, 1978), novelty P3a (e.g., Knight \& Scabini, 1998), P3a (e.g., Katayama \& Polich, 1998; Knight, 1997; Squires et al., 1975), novelty N200-P300 (e.g., Knight, 1986), and P2_P3a (e.g., Daffner et al., 1998; Buadena et al., 1995; Hillyard \& Picton, 1987; Naatanen \& Gaillard, 1983; Naatanen \& Picton, 1986; Snyder \& Hillyard, 1976). The name chosen by researchers seems to depend on several factors. When the nature of the evoking stimuli (as infrequent, highly unusual deviant stimuli) is emphasized, the term novelty is usually included. When the scalp distribution and latency are emphasized (i.e., anterior location, earlier onset), the term P3a is often used. The P3a wave has been easiest to observe in response to infrequent stimuli that are supposed to be ignored. When the $\mathrm{P} 3$ peak is measured against the prior N2 peak and not the prestimulus baseline, the term $\mathrm{N} 2-\mathrm{P} 3$ is employed. In the current study, we chose to use the term novelty $\mathrm{N} 2-\mathrm{P} 3$ wave, based on the nature of the evoking stimuli and the measurement of the peak-to-peak amplitude. In a prior study (Daffner et al., 1998) summarized in the text, the N2-P3 peak-to-peak amplitude and not the P3 (baseline to peak) amplitude predicted viewing durations on novel relative to background stimuli both across and within subjects. However, our focus on the N2-P3 wave complex does not imply that the $\mathrm{N} 2$ and $\mathrm{P} 3$ subcomponents reflect identical aspects of the processing of deviant stimuli. This important issue is the subject of a separate report (Daffner et al, 2000b, in press).

2. It is a logical necessity that stimuli, which have never been encountered before (i.e., those that deviate from long-term contexts), must also deviate from immediate context. Thus, experimentally, it is not possible to directly compare stimuli that only deviate from immediate context with those that only deviate from long-term contexts. The current study's strategy was to compare stimuli that deviated only from immediate context with stimuli that deviated from both immediate and long-term contexts to determine whether the latter had an additional influence.

3. This pattern contrasted with the parietal maximum of the $\mathrm{N} 2-\mathrm{P} 3$ for target stimuli in all the three tasks (main effect of electrode site, midline sites: $F(2,46)=40.36, p<.00005)$, which was more posteriorly distributed than the other two stimulus types (stimulus type by electrode sites interaction, midline sites: $F(4,92)=26.36, p<.00005)$. The $\mathrm{N} 2-\mathrm{P} 3$ response to target stimuli did not differ across tasks, and there were no task by electrode site interactions.

4. This association was not found when looking at P3 (baseline to peak) amplitude rather than $\mathrm{N} 2-\mathrm{P} 3$ peak-to-peak amplitude.

5. Although we suspect that the response is driven by unfamiliarity with a stimulus, the way in which the current experiment was designed cannot disambiguate unfamiliarity from complexity. The unusual stimuli presented also tended to be more complex. Future experiments could compare the impact of deviant stimuli that were unfamiliar, but relatively simple (e.g., a distorted triangle) with deviant stimuli that were both unfamiliar and complex.

6. Note that stimulus duration was longer than the time course of the N2-P3 in all cases, including those with the shortest viewing times. This suggests that the correlation between viewing duration and N2-P3 amplitude is not confounded by the impact of stimulus offset on the N2-P3 response.

\section{REFERENCES}

Alain, C., Richer, F., Achim, A., \& Saint Hilaire, J.-M. (1989). Human intracerebral potentials associated with target, novel, and omitted auditory stimuli. Brain Topography, 1, $237-245$.

Baddeley, A. (1992). Working memory, Science, 255, 556-559.

Baudena, P., Halgren, E., Heit, G., \& Clarke, J. M. (1995). Intracerebral potentials to rare target and distractor auditory and visual stimuli: III. Frontal cortex. Electroencephalography and Clinical Neurophysiology, 94, $251-264$.

Berlyne, D. E. (1960). Conflict, Arousal and Curiosity. New York, NY: McGraw-Hill.

Comerchero, M. D., \& Polich, J. (1998). P3a, perceptual distinctiveness, and stimulus modality. Cognitive Brain Research, 7, 41-48.

Courchesne, E. (1978). Changes in P3 waves with event-related repetition: Long-term effects on scalp distribution and amplitude. Electroencephalography and Clinical Neurophysiology, 45, 754-766.

Courchesne, E., Courchesne, R. Y., \& Hillyard, S. A. (1978). The effect of stimulus deviation on $\mathrm{P} 3$ waves to easily recognized stimuli. Neuropsychologia, 16, 189-199.

Courchesne, E., Hillyard. S. A., \& Galambos, R. (1975). Stimulus novelty, task relevance and the visual evoked potential in man. Electroencephalography and Clinical Neurophysiology, 39, 131-143.

Daffner, K. R., Mesulam, M. M., Scinto, L. F. M., Acar, D., Calvo, V., Faust, R., Chaberie, A., Kennedy, B., \& Holcomb, P. (2000a, in press). The central role of prefrontal cortex in directing attention to novel events. Brain.

Daffner, K. R., Mesulam, M. M., Scinto, L. F. M., Calvo, V., Faust, R., \& Holcomb, P. J. (2000b, in press). An electrophysiologic index of stimulus unfamiliarity. Psychophysiology.

Daffner, K. R., Mesulam, M. M., Scinto, L. F. M., Cohen, L. G., Kennedy, B. P., West, W. C., \& Holcomb, P. J. (1998). Regulation of attention to novel stimuli by frontal lobes: An event-related potential study. NeuroReport, 9, $787-791$.

Daffner, K. R., Mesulam, M. M., West, W., \& Holcomb, P. (1996). The relationship between novelty ERPs (N2-P3a) and subsequent allocation of attentional resources to visual stimuli. (Abstract) Presented at the 3rd Annual Meeting of the Cognitive Neuroscience Society, San Francisco, CA.

Daffner, K. R., Scinto, L. F. M., Weintraub, S., Guinessey, J., \& Mesulam, M. M. (1992). Diminished curiosity in patients with probable Alzheimer's disease as measured by exploratory eye movements. Neurology, 42, 320-328.

Daffner, K. R., Scinto, L. F. M., Weintraub, S., Guinnessey, J., \& Mesulam, M. M. (1994). The impact of aging on curiosity as measured by exploratory eye movements. Archives of Neurology, 51, 368-376.

Desmedt, J. E. (1981). Scalp-recorded cerebral event-related potentials in man as point of entry into the analysis of cognitive processing. In F. O. Schmitt, F. G. Worden, G. Adelman, \& S. D. Dennis (Eds.), Organization of the cerebral cortex (pp. 441-473). Cambridge, MA: MIT Press.

Donchin, E. (1981). Surprise! ... surprise? Psychophysiology, $18,493-513$.

Donchin, E., \& Coles, M. G. H. (1988). Is the P300 component a manifestation of context updating? Behavioral and Brain Sciences, 11, 357-374.

Duncan-Johnson, C. C., \& Donchin, E. (1977). On quantifying surprise: The variation in event-related potentials with subjective probability. Psychophysiology, 14, 456-467.

Escera, C., Alho, K., Winkler, I., \& Naatanen, R. (1998). Neural mechanisms of involuntary attention to acoustic novelty and change. Journal of Cognitive Neuroscience, 10, $590-604$. 
Fiske, D. W., \& Maddi, S. R. (Eds.) (1961). Functions of varied experience. Homewood, IL: Dorsey.

Fuster, J. M. (1989). The prefrontal cortex: Anatomy, physiology, and neuropsychology of the frontal lobe (2nd ed.). New York, NY: Raven.

Geisser, S., \& Greenhouse, S. (1959). On methods in the analysis of profile data. Psychometrika, 24, 95-112.

Goldman-Rakic, P. S. (1987). Circuitry of primate prefrontal cortex and regulation of behavior by representational memory. In F. Plum, V. B. Mountcastle, \& S. T. Geiger (Eds.), The handbook of physiology. Section 1: The nervous system. Volume 5: Higher functions of the brain. Part 1 (pp. 373417). Bethesda, MD: American Physiological Society.

Halgren, E., Baudena, P., Clarke, J. M., Hiet, G., Liegeois, C., Chauvel, P., \& Musolino, A. (1995a). Intracerebral potentials to rare target and distractor auditory and visual stimuli: I. Superior temporal plane and parietal lobe. Electroencephalography and Clinical Neurophysiology, 94, 191-220.

Halgren, E., Baudena, P., Clarke, J. M., Heit, G., Marinkovic, K., Devaux, B., Vignal, J. P., \& Biraben, A. (1995b). Intracerebral potentials to rare target and distractor auditory and visual stimuli: II. Medial, lateral and posterior temporal lobe. Electroencephalography and Clinical Neurophysiology, 94, $229-250$.

Hillyard, S. A., \& Picton, T. W. (1987). Higher functions of the brain. Part 2. In F. Plum, V. B. Mountcastle, \& S. T. Geiger (Eds.), The handbook of physiology. Section I: The nervous system. Volume 5 (pp. 519-584). Bethesda, MD: American Physiological Society.

Holdstock, J. S., \& Rugg, M. D. (1995). The effect of attention on the P300 deflection elicited by novel sounds. Journal of Psychophysiology, 9, 18-31.

Humphrey, N. K. (1972). 'Interest' and 'Pleasure': Two determinants of a monkey's visual preferences. Perception, 1, $395-416$.

Hunt, J. McV. (1965). Intrinsic motivation and its role in psychological development. In D. Levine (Ed.), Nebraska symposium on motivation. Volume 8 (pp. 189-282). Lincoln, NB: University of Nebraska Press.

Johnson, R., Jr. (1986). A triarchic model of P300 amplitude. Psychophysiology, 23, 367-384.

Kahneman, D. (1973). Attention and effort. Englewood Cliffs, NJ: Prentice-Hall.

Katayama, J., \& Polich, J. (1998). Stimulus context determines P3a and P3b. Psychophysiology, 35, 23-33.

Knight, R. T. (1984). Decreased response to novel stimuli after prefrontal lesions in man. Electroencephalography and Clinical Neurophysiology, 59, 9-20.

Knight, R. T. (1986). In M. M. Mesulam (Ed.), Principles of Behavioral Neurology (pp. 327-446). Philadelphia, PA: F. A. Davis.

Knight, R. T. (1996). Contribution of human hippocampal region to novelty detection. Nature, 383, 256-259.

Knight, R. T. (1997). Distributed cortical network for visual attention. Journal of Cognitive Neuroscience, 9, 75-91.

Knight, R. T., \& Scabini, D. (1998). Anatomic bases of eventrelated potentials and their relationship to novelty detection in humans. Journal of Clinical Neurophysiology, 15, 3-13.

Kosslyn, S. M., Alpert, N. M., Thompson, W. L., Chabris, C. F., Rauch, S. L., \& Anderson, A. K. (1994). Identifying objects seen from different viewpoints: A PET investigation. Brain, 117, $1055-1071$.

Kounios, J. H., \& Holcomb, P. J. (1994). Concreteness effects in semantic processing: Event-related potential evidence supporting dual-coding theory. Journal of Experimental Psychology, Learning, Memory, and Cognition, 20, 804-823.
Kroll, J. F., \& Potter, M. C. (1984). Recognizing words, pictures, and concepts: A comparison of lexical, object and reality decisions. Journal of Verbal Learning and Verbal Behavior, 23, 39-66.

Loftus, G. R., \& Mackworth, N. H. (1978). Cognitive determinants of fixation location during picture viewing. Journal of Experimental Psychology: Human Perception and Performance, 4, 565-572.

Mackworth, N. H., \& Morandi, A. J. (1967). The gaze selects informative details within pictures. Perceptual Psychophysiology, 2, 547-552.

McCarthy, G. (1995). Functional neuroimaging of memory. The Neuroscientist, 1, 155-163.

McCarthy, G., \& Wood, C. C. (1985). Scalp distributions of event-related potentials: Ambiguity associated with analysis of variance models. Electroencephalography and Clinical Neurophysiology, 62, 203-208.

Metcalfe, J. (1993). Novelty monitoring, metacognition, and control in a composite holographic associative recall model: Implications for Korsakoff amnesia. Psychological Review, 100, 3-22.

Naatanen, R. (1992). Attention and brain function. Hillsdale, NJ: Erlbaum.

Naatanen, R., \& Gaillard, A. W. K. (1983). The orienting reflex and the N2 deflection of the event-related potential (ERP). In A. W. K. Gaillard, \& W. Ritter (Eds.), Tutorials in ERP research: Endogenous components (pp. 119-141). New York, NY: North-Holland.

Naatanen, R., \& Picton, T. W. (1986). N2 and automatic versus controlled processes. In W. C. McCallum, R. Zappoli, \& F. Denoth (Eds.), Cerebral psychophysiology: Studies in event-related potentials (pp. 169-186). New York, NY: Elsevier.

Noton, D., \& Stark, L. (1971). Eye movements and visual perception. Scientific American, 224, 34-43.

Öhman, A. (1979). The orienting response, attention and learning: An information-processing perspective. In H. D. Kimmel, E. H. Van Olst, \& J. F. Orlebeke (Eds.), The orienting reflex in bumans (pp. 443-471). Hillsdale, NJ: Erlbaum.

Picton, T. W. (1992). The P300 wave of the human event-related potential. Journal of clinical neurophysiology, 9, 456-479.

Posner, M. I. (1986). Chronometric explorations of mind. New York, NY: Oxford University Press.

Ritter, W., Vaughan, H. G., Jr., \& Costa, L. D. (1968). Orienting and habituation to auditory stimuli: A study of short term changes in average evoked responses. Electroencephalography and Clinical Neurophysiology, 25, 550-556.

Rohrbaugh, J. W. (1984). The orienting reflex: Performance and central nervous system manifestations. In R. Parasuraman, \& D. R. Davies (Eds.), Varieties of attention (pp. 323-364). New York, NY: Academic Press.

Roth, W. T. (1973). Auditory evoked responses to unpredictable stimuli. Psychophysiology, 10, 125-138.

Ruchkin, D. S., \& Sutton S. (1978). Equivocation and P300 amplitude. In D. Otto (Ed.), Multidisciplinary perspectives in event-related potential research (pp. 175-177). Washington, DC: US Government Printing Office/EPA.

Snyder, E., \& Hillyard, S. A. (1976). Long-latency evoked potentials to irrelevant, deviant stimuli. Behavioral Biology, 16, $319-331$.

Sokolov, E. N. (1963). Perception and the conditioned reflex. New York, NY: Pergamon.

Squires, N. K., Squires, K. C., \& Hillyard, S. A. (1975). Two variables of long-latency positive waves evoked by unpre- 
dictable auditory stimuli in man. Electroencephalography and Clinical Neurophysiology, 38, 387-401.

Sutton, S., Braren, M., Zubin, J., \& John, E. R. (1965). Evokedpotential correlates of stimulus uncertainty. Science, 150, $1187-1188$

Tulving, E., Markowitsch, H. J., Craik, F. I. M., Habib, R., \& Houle, S. (1996). Novelty and familiarity activations in PET studies of memory encoding and retrieval. Cerebral Cortex, $6,71-79$.

Ungerlieder, L. G., Courtney, S. M., \& Haxby, J. V. (1998). A neural system for human visual working memory. Proceedings of the National Academy of Sciences, U.S.A., 95, $883-890$.
Vurpillot, E. (1968). The development of scanning strategies and their relation to visual differentiation. Journal of Experimental Child Psychology, 6, 632-650.

Wood, C. C., \& McCarthy, G. (1985). A possible frontal lobe contribution to scalp P3. Society of Neuroscience Abstracts, 11, 879 .

Yamaguchi, S., \& Knight, R. T. (1991a). P300 generation by novel somatosensory stimuli. Electroencephalography and Clinical Neurophysiology, 78, 50-55.

Yamaguchi, S., \& Knight, R. T. (1991b). Anterior and posterior association cortex contributions to the somatosensory P300. Journal of Neuroscience, 11, 2039-2054. 
Copyright of Journal of Cognitive Neuroscience is the property of MIT Press and its content may not be copied or emailed to multiple sites or posted to a listserv without the copyright holder's express written permission. However, users may print, download, or email articles for individual use. 